Conference Paper

\title{
Evaluating the REF2014 Results in Art and Design
}

Earnshaw R.A., Liggett S. and Excell P.S.

This is a paper presented at the Internet Technologies and Applications (ITA 2015), 8-11 Sept 2015, Glyndŵw University, Wrexham, UK.

Copyright of the author(s). Reproduced here with their permission and the permission of the conference organisers.

Recommended citation:

Earnshaw R.A., LiggettS. and Excell P.S. (2015) 'Evaluating the REF2014 Results in Art and Design', Proceedings of Internet Technologies and Applications (ITA2015), 8-11 Sept 2015, Glyndŵr University, Wrexham, UK. doi:10.1109/ITechA.2015.7317458 


\title{
Evaluating the REF2014 Results in Art and Design
}

\author{
R. A. Earnshaw, S. Liggett and P. S. Excell \\ Glyndwr University, \\ Wrexham, Wales, UK \\ \{r.earnshaw, s.liggett, p.excell\}@glyndwr.ac.uk
}

\begin{abstract}
In the UK, periodic assessment of research in universities has taken place since 1986. The most recent took place during 2014 with the results being published at the end of the year. This evaluation is concerned with art and design though all disciplines were included in the assessment. The method used for assessing research quality is outlined and the results summarised. The lessons drawn from the evaluation by REF2014 are detailed. A number of issues are identified and discussed. These include the staff selected for submission, the method of evaluation, and a cost-benefit analysis of the process.
\end{abstract}

Keywords-research assessment; quality profile; research outputs; research impact; research environment; practice-based research; interdisciplinarity; metrics

\section{INTRODUCTION}

The UK has had periodic research evaluation exercises from 1986 onwards, and approximately every five years, on behalf of the four UK higher education funding councils (HEFCE, SHEFC, HEFCW, DELNI). Submissions from each subject area (or "unit of assessment") were given a quality ranking by a subject specialist peer review panel composed of experts in the field. The rankings were used to inform the allocation of quality weighted research funding (QR) that higher education institutions might receive (if their outcomes were above a threshold) from their national funding council for each of the years between research assessments [1].

Over the period of the assessments the formula for allocation of QR has resulted in the funding becoming more selective. Following the assessment in 2008, the ratio of the subsequent QR funding allocation across $4^{*}, 3^{*}, 2^{*}$, and $1^{*}$ rankings was 7:3:1:0. From 2012 the ranking of $2^{*}$ no longer received any financial allocation, so funding was limited to those areas with $4^{*}$ and $3^{*}$ rankings and the ratio of funding was $3: 1$. It was replaced by the Research Excellence Framework (REF) in 2014, though the method of assessment has produced similar results to those in earlier evaluations. The funding formula for QR following REF2014 was announced as $4: 1$ (ratio of $4 *$ to $3 *$ ) by the funding council in February 2015, and will determine the distribution of approximately $£ 1.6$ billion of research funding annually from the UK funding councils starting with 2015-16. Thus selectivity in funding has been increased though it has been argued that because of the overall rise in $4^{*}$ and $3^{*}$ research, the changing of the ratio for funding would have minimum effect.

\section{ASSESSING RESEARCH QUALITY}

\section{A. Research Quality}

The primary criteria used in the evaluation of research quality in REF2014 were originality, significance and rigour. In general, these are accepted internationally as key measures of research excellence. These criteria were used to assess the quality of the research outputs (generally the four works submitted for full-time faculty for the period 1 January 2008 to 31 December 2013). Research outputs contributed $65 \%$ to the overall quality profile. Further components in the evaluation were the impact (based on a selected number of submitted case studies) and environment (based on the characteristics of the area in the institution where the research was done). Impact counted $20 \%$ and environment $15 \%$ [2]. Impact was a new category introduced in this assessment and, prior to the publication of the outcomes, was the subject of considerable discussion and disagreement on the part of researchers; subsequently, the criticisms have been much more muted.

\section{B. Research Outputs}

Research outputs in the majority of the discipline areas were predominantly publications in the open literature. It is generally accepted that the extent of the peer reviewing involved in such publications may contribute in some degree to their quality. However, neither the impact factor of the researcher nor the impact factor of the publication vehicle were formally taken into account in the evaluation. The publication was evaluated by a number of expert reviewers on the panel and then ranked by agreement across the reviewers. However, it is clear that it would be difficult for such reviewers to be unaware of the status of the researcher or the publication vehicle, as blind reviewing was not used. Subject panels had international representation for the purposes of benchmarking the UK evaluation.

In creative discipline areas, the types of research outputs accepted as being valid to be awarded high scores $\left(4^{*}\right.$ and $\left.3^{*}\right)$ were much wider, in particular including creative artefacts and art exhibitions, although evidence of international significance and of the intellectual aspect of the creative process were normally required for high scores to be awarded.

The ranking of each output was according to the definitions in Table 1. These rankings were then included in a profile distribution of all outputs within a particular submission. Thus it is not possible to determine from the published results which output (and therefore which member of staff) contributed to each rank. In this sense therefore, the results are essentially 
anonymised. However, if a submission only contained a small number of people, then it could be possible to identify which person contributed to high ranked outputs and which to low rankings - as all the outputs (i.e. the reference data for the published paper or book) are included in the published results for REF2014. One exception is where the output contained information of commercial sensitivity which was submitted in confidence by the institution and which was then evaluated in confidence. Not to be able to include such work would have disadvantaged institutions with significant commercial contracts and where it was not possible to publish the results of the work in the open literature.

The criteria for assessing the quality of outputs are 'originality, significance and rigour' as summarised in Table 1.

TABle 1: OUtPuts Sub-PROFILE: CRITERIA AND DEFINITIONS OF STARRED LEVELS.

\begin{tabular}{|l|l|}
\hline Ranking & Specification \\
\hline Four star & $\begin{array}{l}\text { Quality that is world-leading in terms of originality, } \\
\text { significance and rigour. }\end{array}$ \\
\hline Three star & $\begin{array}{l}\text { Quality that is internationally excellent in terms of } \\
\text { originality, significance and rigour but which falls short } \\
\text { of the highest standards of excellence. }\end{array}$ \\
\hline Two star & $\begin{array}{l}\text { Quality that is recognised internationally in terms of } \\
\text { originality, significance and rigour. }\end{array}$ \\
\hline One star & $\begin{array}{l}\text { Quality that is recognised nationally in terms of } \\
\text { originality, significance and rigour. }\end{array}$ \\
\hline $\begin{array}{l}\text { Quality that falls below the standard of nationally } \\
\text { recognised work. Or work which does not meet the } \\
\text { published definition of research for the purposes of this } \\
\text { assessment. }\end{array}$ \\
\hline
\end{tabular}

Attention in recent years by funding bodies has not only been on research, but also on assessing the extent to which the results of the research have subsequently been utilised by companies, public bodies, and the wider society beyond the academy. This could be in terms of the beneficial impact on industry, particularly if the research has led to new patents, products, processes or procedures which have improved business efficiency and effectiveness or improved the position of UK businesses in world markets, or else verifiable social benefits in health, well-being, employment, etc. Such assessment of impact was not confined to business or industry but included all forms of societal and cultural value. The latter have special relevance for the arts and humanities.

The evaluation of impact [2] was done using the case studies and measured the degree of reach and significance of the work included in each of the case studies submitted. This implies that the research outputs included within each case study had to have a degree of applicability to, and recognition by, one or more aspects of the wider business and societal environment. Thus for art and design, such case studies included creative works in a variety of forms including exhibitions, installations, applications, media works, collaborations, etc. The case studies had to have a research content of at a rank of at least $2 *$. Again the results are anonymised since it is not possible to determine the score for a particular case study (unless only one was submitted). Thus there is no opportunity to challenge the evaluation subsequently.
The ranking of the impact in the case studies was according to the definitions in Table 2.

TABLE 2: IMPACT SUB-PROFILE: CRITERIA AND DEFINITIONS OF STARRED LEVELS.

\begin{tabular}{|l|l|}
\hline Ranking & Specification \\
\hline Four star & $\begin{array}{l}\text { Outstanding impacts in terms of their reach and } \\
\text { significance. }\end{array}$ \\
\hline Three star & $\begin{array}{l}\text { Very considerable impacts in terms of their reach and } \\
\text { significance. }\end{array}$ \\
\hline Two star & $\begin{array}{l}\text { Considerable impacts in terms of their reach and } \\
\text { significance. }\end{array}$ \\
\hline One star & $\begin{array}{l}\text { Recognised but modest impacts in terms of their } \\
\text { reach and significance. }\end{array}$ \\
\hline Unclassified & $\begin{array}{l}\text { The impact is of little or no reach and significance; or } \\
\text { the impact was not eligible; or the impact was not } \\
\text { underpinned by excellent research produced by the } \\
\text { submitted unit }\end{array}$ \\
\hline
\end{tabular}

Previous research assessments did not include impact per $s e$, but used a less verifiable concept of 'esteem', which may be said to equate to direct and indirect measures of impact such as could be accomplished by evaluating such aspects as patents, citations in news media, industrial recognition, and economic significance. To provide greater externality at REF2014, evaluations of impact in art and design were also performed by key representatives of local government, publishing, arts nongovernmental organisations, the design industries and the public museum service. However, it is still not certain how accurate or useful such measures are when determining the longer term value of research, particularly pure research, when the measurement is done on a short term basis. However, this point has been raised in the context of discussions about future assessments, where it could be possible to track how far these same areas have increased their impact over time, essentially giving a longer time frame for overall assessment.

With regard to the research environment, the reviewers assessed this in terms of its vitality and sustainability [2] including its contribution to the vitality and sustainability of the wider discipline or research base. The ranking of research environment was according to the definitions in Table 3.

TABle 3: ENVIRONMENT SUB-PROFILE: CRITERIA AND DEFINITIONS OF STARRED LEVELS

\begin{tabular}{|l|l|}
\hline Ranking & Specification \\
\hline Four star & $\begin{array}{l}\text { An environment that is conducive to producing } \\
\text { research of world-leading quality, in terms of its } \\
\text { vitality and sustainability. }\end{array}$ \\
\hline Three star & $\begin{array}{l}\text { An environment that is conducive to producing } \\
\text { research of internationally excellent quality, in terms } \\
\text { of its vitality and sustainability. }\end{array}$ \\
\hline Two star & $\begin{array}{l}\text { An environment that is conducive to producing } \\
\text { research of internationally recognised quality, in } \\
\text { terms of its vitality and sustainability. }\end{array}$ \\
\hline One star & $\begin{array}{l}\text { An environment that is conducive to producing } \\
\text { research of nationally recognised quality, in terms of } \\
\text { its vitality and sustainability. }\end{array}$ \\
\hline Unclassified & $\begin{array}{l}\text { An environment that is not conducive to producing } \\
\text { research of nationally recognised quality. }\end{array}$ \\
\hline
\end{tabular}

\section{RESULTS OF THE EVALUATION}

The submissions and the results for Art and Design were published online [3, 4]. The Times Higher Education lists the 
results by the overall performance of institutions and also by subject [5]. Table 4 gives the average profiles for the ranking categories for all the submissions in art and design [6].

$\begin{array}{lc}\text { Summary Data for Art and Design (all submissions) } \\ \text { Number of submissions } & 84 \\ \text { Category A FTE staff submitted } & 1,604 \\ \text { Category A and C staff submitted } & 2,027 \\ \text { Career researchers } & 301 \\ \text { No of outputs submitted } & 6,356 \\ \text { No of case studies submitted } & 239\end{array}$

TABLE 4 AVERAGE SUB-PROFILES (\%) FOR ALL SUBMISSIONS IN ART AND DESIGN (FTE WEIGHTED) [6].

\begin{tabular}{|l|l|l|l|l|l|}
\hline & $\mathbf{4}^{*}$ & $\mathbf{3}^{*}$ & $\mathbf{2}^{*}$ & $\mathbf{1}^{*}$ & $\mathbf{U} / \mathbf{C}$ \\
\hline Overall & 26 & 42 & 25 & 6 & 1 \\
\hline Outputs & 18.5 & 42.6 & 30 & 7.7 & 1.2 \\
\hline Impact & 36.6 & 44.7 & 13.6 & 3.9 & 1.2 \\
\hline Environment & 40.5 & 40.8 & 15.5 & 3 & 0.2 \\
\hline
\end{tabular}

The profile of outputs is not untypical of other disciplines. However, the scores for both impact and environment are significantly higher than those for outputs in the $4^{*}$ category. Similar differences occurred in most disciplines. The overall impact across all disciplines scored an average of 3.24 (out of 4) compared with an average of 2.90 for outputs. One possible cause of this is that as the case studies were only four pages long, they were easier to assess. A further possibility is that some reviewers of case studies could have graded more leniently than for outputs in order to seek to influence funders and politicians in favour of their discipline [7]. Many of the outputs as published papers containing the detailed results of research would take a substantial amount of review time. This in turn would give more scope for reviewers to find questions or issues with regard to the published work and, if in doubt, mark it down a grade.

However, it has been noted that one case study was required per 10 faculty submitted, so the lower number of case studies submitted compared to outputs could give a higher margin for error. The difference between a $4^{*}$ and a $3 *$ rating for one case study could be significant in terms of its overall effect on the grade. In addition, because the scores for impact and environment show a wider variation than for outputs, they count more than their specified weighting in determining the overall score. On this basis impact counted overall for $29 \%$ (rather than 20\%) and outputs 47\% (rather than 65\%) across all disciplines. This also explains the large numbers of REF submissions across all subjects that contain staff numbers just below the threshold required for submitting an extra case study. This could have had a distorting effect not only on the results of the REF, but also on the future careers of those staff who were excluded. In other words, what is being measured may not reflect the reality on the ground in the institution in terms of overall research culture and research strength. This could be used as an argument in future to require the inclusion of all eligible staff in the submission for assessment, which would avoid strategies that institutions clearly adopted with regard to the numbers of staff included, in an attempt to optimise the position of the institution and its discipline areas in league tables.
The results of the highest performing submissions in art and design are shown in Table 5 when ranked according to grade point average [5].

TABLE 5 RANK ORDER By GPA IN ART AND DESIGN.

\begin{tabular}{|l|l|l|l|l|l|}
\hline $\begin{array}{l}\text { Rank } \\
\text { order }\end{array}$ & Institution & $\begin{array}{l}\text { FTE } \\
\text { staff }\end{array}$ & \% of 4* & GPA & $\begin{array}{l}\text { Research } \\
\text { Power }\end{array}$ \\
\hline 1 & Reading B & 8 & 56 & 3.51 & 29 \\
\hline 2 & Courtauld & 33 & 56 & 3.49 & 113 \\
\hline 3 & Westminster & 24 & 45 & 3.36 & 81 \\
\hline 4 & St Andrews & 13 & 38 & 3.30 & 42 \\
\hline 5 & York & 19 & 47 & 3.29 & 62 \\
\hline 6 & Manchester & 12 & 42 & 3.26 & 37 \\
\hline 7 & Ulster & 25 & 47 & 3.24 & 80 \\
\hline$=8$ & Sheffield Hallam & 24 & 42 & 3.22 & 79 \\
\hline$=8$ & UCL A & 17 & 37 & 3.22 & 55 \\
\hline 10 & Essex & 5 & 32 & 3.21 & 15 \\
\hline 11 & Warwick & 11 & 40 & 3.19 & 35 \\
\hline 12 & Soas & 10 & 35 & 3.16 & 31 \\
\hline 13 & Leeds A & 16 & 34 & 3.15 & 49 \\
\hline 14 & Open & 23 & 29 & 3.13 & 73 \\
\hline
\end{tabular}

Research power is an alternative metric derived from the results and includes both the quality of the research and the number of staff submitted, thus it is a measure of the volume factor in the research. It has been argued that this favours large departments (who may have still omitted staff from the submission) and a more accurate measure would be to use the proportion of eligible staff submitted. This would give an intensity-weighted GPA. Tables have been also published using this methodology [8]. The results are broadly comparable with Table 5 but it does cause some institutions to drop out of the top 15 and others to enter where the proportion of submitted staff (compared to total eligible staff) was relatively low.

The number of PhDs completed may be used as a measure of research culture, though other factors could be used such as total research and contract income for the period. It can be argued that $\mathrm{PhD}$ completions also includes an element of impact since the training received by $\mathrm{PhD}$ students is then used by them subsequently in a variety of external contexts beyond their original training. The well-established centres for Art and Design in the UK did well on both PhD completions and also total research income (Table 6).

TABlE 6. RESUlts FOR ART AND DESIGN WITH HIGHEST NUMBERS OF PHD COMPLETIONS, 2008-13.

\begin{tabular}{|l|l|l|l|l|}
\hline Institution & $\begin{array}{l}\text { Staff } \\
\text { Submi } \\
\text { tted } \\
\text { FTE }\end{array}$ & $\begin{array}{l}\text { Impact } \\
\text { Case } \\
\text { Studies }\end{array}$ & $\begin{array}{l}\text { PhDs } \\
\text { awarded } \\
\mathbf{2 0 0 8 - 1 3}\end{array}$ & $\begin{array}{l}\text { Total } \\
\text { Research } \\
\text { Income } \\
\mathbf{2 0 0 8 - 1 3} \\
\text { (million) }\end{array}$ \\
\hline $\begin{array}{l}\text { Courtauld Institute } \\
\text { of Art }\end{array}$ & 32.5 & 4 & 84 & $£ 5.747$ \\
\hline $\begin{array}{l}\text { Royal College of } \\
\text { Art }\end{array}$ & 59.55 & 7 & 57 & $£ 6.848$ \\
\hline UCL & 36 & 6 & 42 & $£ 0.404$ \\
\hline Univ of the Arts & 109.7 & 12 & 63 & $£ 8.011$ \\
\hline Goldsmiths & 31.3 & 4 & 48 & $£ 3.848$ \\
\hline Loughborough & 54.73 & 6 & 87 & $£ 11.162$ \\
\hline
\end{tabular}




\section{LESSONS FROM THE OVERVIEW REPORTS}

The overview report from the sub-panel responsible for art and design detailed a number of the significant features of the submissions [9]. These are summarised below in three categories - strengths, weaknesses, and observations.

\section{A. Strengths}

There was an increased proportion of innovative and productive interdisciplinary research compared to 2008, particularly within areas of product and digital design, film, curatorship, media studies, conceptual and performance-based art practice. The majority of the interdisciplinarity resulted from collaborations with disciplines outside art and design and included engineering, physical sciences, computer science, health, medical, languages, drama, dance and performing arts. Practice-based research is a key feature of art and design and the submissions confirmed that the sector is a leader in this area of research activity, and in the elaboration of emergent approaches to knowledge. There was also growth at the interface between traditional practice and the innovative use of digital technology. Collaboration between practitioners and museums has led to advances in archival environments. Exhibitions and conservation studies were evident across all subject areas and demonstrated strength.

\section{B. Weaknesses}

The intellectual and theoretical underpinning of graphic and communication design was regarded as weak. There was evaluative commentary on esteem, impact and status of the outputs, such as by reviews and publicity materials, rather than providing an explanation of the significance of the research. This was felt to be a deficiency. Some of the output portfolios contained highly disparate materials without explanation or elaboration, which again was regarded as weak.

\section{Observations}

Contemporary art featured prominently as expected. However, art history outputs showed the continuing importance of work in earlier periods including Byzantine, Medieval and Renaissance studies. Cross-cultural and interdisciplinary studies reflected a dynamic expansion of the frontiers of the discipline. All forms of publications (books, journals, etc) comprised $57 \%$ of the outputs across art history and art and design practice, whereas artefacts only comprised $11 \%$. There was an increased range of exhibition activity compared to 2008, including museums, galleries, festivals and local authorities. Social and economic impact of the work was substantial with $81 \%$ being judged at the highest quality levels. In addition, $81 \%$ of the research environment described by submitted institutions was judged to be world-leading and/or internationally excellent. Some institutions had obtained large amounts of funding during the period and had also been very successful in large numbers of $\mathrm{PhD}$ completions.

\section{DISCUSSION}

A number of points arise from this consideration. These include the degree of reach of the assessment (as all academic staff are not included because each institution makes a selection according to how it perceives the way to obtain the best result), other methods of evaluation, the cost effectiveness of the evaluation, and opportunities lost due to the time and money spent on the evaluation. These points would apply to all disciplines in the assessment, not just art and design. In areas where art and design raise separate issues with regard to the points raised these are noted.

\section{A. Staff selection}

The selective inclusion of staff, as noted earlier, can have a distorting effect not only on the results of the REF, but also on the future careers of those staff who were excluded. In other words, what is being measured is only a sub-section of a department or institution. Additional measures calculated and published by other bodies such as research-power, or researchintensity, are seeking to make the research culture and research strength of a department more explicit. These measures may be of more interest to potential $\mathrm{PhD}$ students or potential members of staff, and even funding bodies. This can be used as an argument to require the inclusion of all eligible staff in future submissions.

\section{B. Use of metrics}

It has been observed from the start of periodic research assessments that other proxies could be used to measure research quality, including research grants, individual and departmental $\mathrm{H}$-index, and $\mathrm{PhD}$ completions. The advantage of these is that their data is already in the system and would not involve the generation of any new data (which costs time and money). Research grants are peer reviewed and are increasingly competitive, so this element of peer review is already in the system. An early evaluation was done in a previous RAE on research grants alone for the engineering area, and the difference between the rankings obtained by detailed review of outputs as in REF2014 compared to the ranking based on research grants alone was less than $0.1 \%$. In the past, using this proxy has been resisted because there was no research council to award grants in the arts and humanities, but now there is - and so this argument is weakened. Also, it is recognised that significant advances in the arts and humanities may be less dependent on large grants since there is less dependence on research laboratories and high-cost specialist equipment. Individual $\mathrm{H}$-index measures both the productivity and citation impact of a person's body of work and is therefore much more wide-ranging than just selecting 4 publications. It has been argued that this metric favours more mature scholars who have been able to build up a substantial body of work over time and therefore younger scholars fare less well on this metric. However, it is the same situation for everyone in all the submissions. It has also been argued that overall it probably gives a more accurate assessment of the quality of published work than, say, two panel members reading 4 publications of a scholar and then giving these a score. If the original papers were submitted to an international journal, they would probably have been more widely read and assessed by international reviewers before publication than they were in the REF. Questions could be asked about the refereeing process essentially being duplicated when it is known to be prone to possible differing judgements, or errors, if the expertise of the 
panel reviewer is not sufficiently close to the research area of the publication $[10,11]$. This is particularly critical at the $4 * / 3 *$ and $3 * / 2 *$ boundaries simply because of the potential financial implications. Since $2^{*}$ research is no longer funded any output ranked below $3^{*}$ will receive no funding. The anonymity of the results prevents the panel members coming under subsequent legal challenge if their evaluation of a publication differs significantly from what the previous reviewing prior to publication had indicated. There is a similar situation with regard to the measurement of impact in the case studies. These are aggregated so it is not possible to determine the rank given for a particular case study. This lack of full openness and transparency in the evaluation of outputs and case studies is out of synchronisation with the requirements of modern methods of assessment. Using departmental $\mathrm{H}$-index (rather than individual) would be equivalent to issuing the results in profile form, and would preserve anonymity, if this requirement were to continue.

Preliminary results have already been published comparing the use of metrics (e.g. such as the Departmental or Research Group H-index for a particular research area) with the results of the peer reviewed research assessments in the UK at 2008 and 2014. For the latter, more work is still to be done but initial results present a fair degree of overall correlation between the use of metrics and the results published from REF2014 in core science and technology areas [12].

It has been noted that the use of H-index in the arts and humanities is less well-accepted, simply because the nature of publication is different. For example, it has been argued that the wide variety of outputs at varying time intervals does not lend itself to citation to the same extent as the more regular publications in science and engineering. However, it was noted in section 4.3 that in the outputs submitted to the REF, 57\% corresponded to traditional forms of publication (books, journals, etc), whereas artefacts only comprised $11 \%$. Thus it is possible for the $57 \%$ to be evaluated by means of metrics; with the remainder being evaluated by a peer review process.

HEFCE is currently carrying out an independent review of the role of metrics in research assessment, which is due to report in Spring 2015 [13]. It is intended that this will inform the funding council and other UK higher education funding bodies with regard to future iterations of national research assessment.

HEFCE is also currently carrying out a review of REF2014 which will inform policy development for the future [14]. This review includes an evaluation of impact of research, assessing multidisciplinary and interdisciplinary research, and the cost of the REF.

\section{Cost-benefit analysis}

Finally, the opportunity-cost in the evaluation is substantial. Estimates of the cost of the assessment vary from $£ 400$ million to $£ 1$ billion. The question has been raised as to whether this is a wise use of resource that could otherwise have been spent in supporting new research. It has been estimated that academic and professional staff in institutions spent up to a year or more preparing their submissions. Panel members spent a year in analysing the submissions and preparing the results for publication. There are also the research opportunities lost by both of these parties essentially taking 2 years out of continuous research. Although the wide-ranging nature of the assessment provides testimony to its fairness and objectivity, if data is already in the system which could be used to give the same results to within $0.1 \%$, then questions need to asked about the overall cost-benefit balance of the process.

\section{CONCLUSIONS}

As noted in section 5.2, HEFCE is currently carrying our reviews of REF2014, and the use of metrics in research assessment.

In 2010, a system for Excellence in Research in Australia (ERA) was devised based primarily on the ranking of journals and conferences on a scale $\mathrm{A}^{*}, \mathrm{~A}, \mathrm{~B}$, and $\mathrm{C}$ [15]. The latter were based broadly on impact factors of the publication vehicles and also peer review of the vehicles, and were approximately equivalent to $4^{*}, 3^{*}, 2^{*}$ and $1^{*}$ in the UK. The databases on ranked journals and conferences are no longer available for inspection [16]. It could be argued that ranking a publication solely on the basis of this database could be inaccurate for those papers that were of excellent quality but were published in lower ranked journals. These databases were no longer used after 2011 and a range of metrics is now used including citation profiles of papers and peer review. The data submitted by universities includes all eligible researchers, and the indicators used have been developed in close consultation with the research community [17]. It is also aimed to minimise the resourcing burden of ERA for Government and universities in order to accomplish the research assessment, and it is clear that the UK also needs to give greater priority to this factor in order to minimise the cost of the REF.

The academic community in the UK recognises the importance of producing internationally leading outputs. It is expected that research selectivity will continue to increase, and the future of research in most institutions other than those with the highest proportion of $4^{*}$ and $3^{*}$ research is unclear given that their QR funding is likely to decrease over time. It is clear that tactical decisions will continue to be made on whether to submit a selection of staff designed to maximise QR funding or reputation (highest possible scores). It takes time and resource in order to make tactical decisions, and this cost has to be added to the overall cost of the process.

Given that measures of impact may have been higher than expected, it is possible that in future more formal methods may be devised to evaluate impact more systematically on a rolling basis.

Art and Design has a degree of overlap with Communications, Culture and Media Studies (UoA 36) and some institutions may have chosen to submit Art and Design work in this category, especially if it was part of a larger research area in media or communications. Thus even with cross-referencing between panels, it is unclear whether it is better to submit a larger submission in one area (for volume) or divide into smaller, more disciplinary-specific, submissions. 


\section{REFERENCES}

[1] "How we fund research", HEFCE http://www.hefce.ac.uk/whatwedo/rsrch/howfundr/

[2] REF2014 Assessment Criteria and Level Definitions, 2014. http://www.ref.ac.uk/panels/assessmentcriteriaandleveldefinitions/

[3] REF2014: Submission data for Art and Design http://results.ref.ac.uk/DownloadSubmissions/ByUoa/34

[4] REF2014: Results for Art and Design: History, Practice and Theory http://results.ref.ac.uk/Results/ByUoa/34

[5] REF2014 - Results by Subject http://www.timeshighereducation.co.uk/features/ref-2014-results-bysubject/2017594.article

[6] REF2014: Average Profile for Art and Design http://www.ref.ac.uk/media/ref/results/AverageProfile 34_Art and Des ign_History_Practice_and_Theory.pdf

[7] P. Jump, "Cracking the Case Studies", Times Higher Education, pp32-41, $19 \quad$ February 2015. http:/www.timeshighereducation.co.uk/tablet/208D85EC/2018555.shar ed

[8] P. Jump, "The Race is not to the Swift", Times Higher Education, pp 3559, 1 January 2015. http://www.timeshighereducation.co.uk/features/ref2014-rerun-who-are-the-game-players/2017670.article

[9] REF2014: Overview Report by Main panel D and Sub-panels 27 to 36,

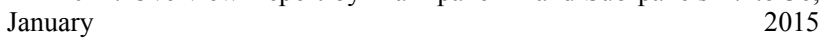
http://www.ref.ac.uk/media/ref/content/expanel/member/Main\%20Panel $\% 20 \mathrm{D} \% 20$ overview\%20report.pdf

[10] D. Sayer, "Rank Hypocrisies: the insult of the REF", SAGE Publications Ltd, pp128, 2015. http://www.amazon.co.uk/Rank-Hypocrisies-Insult$\underline{\text { SAGE- }}$

Swifts/dp/1473906563/ref=sr 13 ?s=books\&ie=UTF8\&qid=142529189 $1 \& \mathrm{sr}=1-3 \&$ keywords $=$ derek + sayer

[11] D. Sayer, "One scholar's crusade against the REF" http://www.timeshighereducation.co.uk/features/one-scholars-crusadeagainst-the-ref/2017405.fullarticle

[12] "Predicting results of the Research Excellence Framework using departmental h-Index” O. Mryglod, R. Kenna, ·Yu. Holovatch, ·B. Berche, Scientometrics, Springer, 23 December 2014. http://link.springer.com/article/10.1007/s11192-014-1512-3

[13] "Independent review of the role of metrics in research assessment" http://www.hefce.ac.uk/whatwedo/rsrch/howfundr/metrics/

[14] "Evaluation of the research excellence framework (REF" http://www.hefce.ac.uk/whatwedo/rsrch/researchassessment/reffeedback

[15] http://www.arc.gov.au/era/era 2010/archive/default.htm

[16] http://www.arc.gov.au/era/era_2010/archive/key_docs 10.htm

[17] http://www.arc.gov.au/era/ 